\title{
Estimation of Commercial Value of Spectrum: The Approach Adopted in Thailand
}

\author{
Settapong Malisuwan, Jesada Sivaraks, Thitipong Nandhabiwat, Navneet Madan, and Pannakorn Laokulrat
}

\begin{abstract}
Mobile communications spectrum is a scarce and essential resource as it is required to satisfy customer demand for telecommunications. Spectrum as a resource if used efficiently can incur maximum economic value for an economy. The aim of this research is to provide a general analytical frameworks and mobile communication spectrum value estimation models that can be utilized to estimate spectrum value. The outcome of this research is to assist National Regulatory Authorities (NRA) in getting a fair value for spectrum in order to ensure that mobile communication spectrum is utilized for high economic value generating technologies.
\end{abstract}

Index Terms - Spectrum value estimation, income approach, economic-wide approach, opportunity cost approach, benchmarking approach, econometric approach.

\section{INTRODUCTION}

Since an Italian physicist named Guglielmo Marconi demonstrated the use of radio electromagnetic spectrum to communicate in 1894, the interest in the radio spectrum has grown to include nations which now represent a majority within the International Telecommunications Union (ITU). As radio spectrum or airwave is a scarce natural resource, the National Regulatory Agencies (NRAs) in each country must assign these recourses wisely for public safety and public service uses. A few decades ago, some NRAs assigned the spectrum to Mobile Network Operators (MNOs) for free of charge as long as MNOs utilize these spectra for the benefit of the country as a whole within the scope of legislation. But now with the exploding demand of spectrum usage from mobile phones, this has prompted majority of NRAs to seek for the most optimal approaches to utilize spectrum effectively and efficiently. This includes reviewing where freeing up spectrum can add the most economic value as well charging for spectrum possession, to encourage efficient use of valuable national resources, especially by preventing "free parking" by inactive holders. Even in the absence of competition, an incumbent holder of frequencies should be given sufficient incentive to vacate or share them for alternative use when not exploiting them fully. Spectrum valuation is neither static nor a set science, but it is kinetic. Additional fact is that the more demand in spectrum usage, the higher value of spectrum would be. Initially, spectrum

Manuscript received March 24, 2013; revised June 2, 2013. This work was supported in full by National Broadcasting and Telecommunications Commission of Thailand (NBTC).

The authors are with the National Broadcasting and Telecommunications Commission (NBTC), Bangkok, Thailand (e-mail: settapong.m@nbtc.go.th, jesada.s@nbtc.go.th, thitipong.n@nbtc.go.th, navneet.m@nbtc.go.th, pannakorn.1@nbtc.go.th). auctions around the world saw a rise in the value of spectrum [1], [2]. Today about a decade later, spectrum auctions have seen a decline in the price of spectrum mainly because operators are more knowledgeable on long-term adverse effects that overbidding on spectrum can have on their business, industry and consumers.

Understanding the value of radio spectrum is crucial. We begin with the analogy of spectrum with land as a radio spectrum possesses similar properties to that of a land. Little can be achieved from small pieces of unconnected lands, but a big piece of land can have a synergistic outcome leading to a tremendous amount of potential hence, it can be used for a great variety of applications. Thus, radio spectrum utilization is only practical for use in connected bands. Different types of spectrum have different value and physical characteristics, hence it may be capable to support certain applications and unable to cater to others. "The value might therefore be better determined by a - technically and commercially informed interested user on a free market, than by historical or administrative considerations by a disinterested public servant" [3]. Now all policy-makers have the same underlying question about spectrum: how much is it worth? In other words, how should one value spectrum? However, careful consideration must be given in estimating spectrum value to achieve the optimal spectrum value. Since, if spectrum value estimation is excessively high, mobile operators will be at a disadvantage hence, operators will be motivated to charge higher prices on consumers to cover up its costs. On the other hand, spectrum value estimation should not be too low as spectrum license holders or in this case mobile operators will be disinterested in utilizing spectrum efficiently.

\section{Estimation of Auction Spectrum VALUE}

Mobile communication spectrum is an essential resource for telecommunications applications and services. It has one of the country's highest economic values. Therefore it is critical that NRAs find choose a suitable approach to estimate the value of available spectra. Spectrum usage fees need to be elevated to a certain extent such that spectrum license holders have an incentive in encouraging efficient utilization and for high economic value generating technologies (International Telecommunications Union (ITU)[3]. Spectrum Value estimation models range from simple to complex and some of these estimation approaches may require an extended period of time. Some NRAs utilize more than one approach to gauge between final outcomes. Since the year 2000, several additional modern estimation models have been originated to ease NRAs inconcluding reserve price of the spectrum to be 
auctioned. This research provides categorized spectrum into five major approaches and their summarized strengths and weaknesses is provided in Table I. Although this paper focuses detailed insight into how spectrum value is assessed using the two well-accepted approaches which are Opportunity Cost and Econometrics, however, the other three approaches are also explained briefly.

\section{A. Income Approach (Business-Based Value)}

This approach estimates spectrum value from a commercial perspective. The goals of both NRA and operator converge at the point when the spectrum is optimally priced. The NRA is interested in economic and technical efficiency whereas the operator is interested in exploiting the profit potential of the assigned spectrum. The philosophies of the income approach involve understanding how much profit the spectrum in question will generate (International Telecommunications Union (ITU), [3]. The analysis requires data on total revenue, capital expenditure (including operating expense) and investment risk cost.

\section{B. Economic-Wide Approach}

Economic-Wide approach assesses the value of spectrum in terms of its contribution to the national economy increasing economic contribution of spectrum translates into increasing value. This approach also examines the impact on economic activity of variables such as economic downturns, changes in taxation, new trade relationships, etc. The model assesses the economy at three levels of aggregation including micro (individual, households, and businesses), meso (productions: agricultures, industries, and service sectors), and lastly macro (country) in order to get a picture of the stimulus to the overall economy assuming there are meaningful connections between and the macro-economy (International Telecommunications Union (ITU) [4].

\section{Benchmarking Approach}

This approach estimates the value of spectrum to be auctioned by comparing its value to spectrum values concluded from past values both within the country and in other countries. In a 2009 report for the Australian Communications and Media Authority (ACMA), ACMA cited three categories of market data that can be used as benchmarks to estimate spectrum auction value, including [5]:

- Spectrum Market Transactions or a "Market Comparable" iswhen value of spectrum in auctions or trades in secondary markets may be used directly to assess value of spectrum. [4]

- Values of Companies - information on the market valuations of firms that hold spectrum rights are a reflection of the value of the spectrum. The value of spectrum can be estimated by deducting the value of other assets from the firm value thereby reaching a conclusion on value of the spectrum. [5]

- Capacity Sales of Spectrum -This involves estimating the spectrum value from the revenue that could be earned from the technology supported by this particular spectrum range. This price gives a spectrum value plus the value of other inputs. The value of spectrum can be estimated by subtracting the value of other inputs from the data of revenue that could be earned by this particular spectrum [5]

\section{Opportunity Cost Approach}

Over a decade ago in preparation on Administrative Incentive Pricing (AIP) in the United Kingdom, the key concept that emerged was what economists call opportunity cost [3]. In principle, the opportunity cost is the amount that a potential bidder would have to encounter before they would quit and go elsewhere to acquire what they required. In terms of mobile communications spectrum, the opportunity cost of a given frequency used is the cost saved as a result of using that frequency rather than its next best alternative. In regards to spectrum, opportunity cost is relevant due to the range of costs and benefits associated with spectrum's role as an input to commercial services.

Assessment of opportunity cost reflects the estimated price markets on spectrum at auction. This involves considering different conditions, such as levels of congestion which differ from band to band. Moreover, Martin Cave, lead researcher on spectrum, stated that the users should "face continuing incentives towards more productive use of spectrum, and such incentives should "be financial and based on opportunity cost of spectrum use. In this way, spectrum would cost as any other input into the production process." Thus, market players could make well-versed judgments about their use of spectrum and available alternatives [6]. The estimation of spectrum value by using this opportunity cost modeling approach can be grouped into two situations: with or without the spectrum acquired.

- Opportunity Cost of Unoccupied Spectrum

Even though spectrum is vacant and not in use, this does not result in zero opportunity cost. It is because when considering other alternatives, one will find that the spectrum still is usable for other means. Besides, when looking at the future use of spectrum, it is valuable because it has the potential to cater to growing population and contributing to growth of the economy. However, the opportunity cost still can be estimated by considering the operating cost in providing services for that spectrum directly and also utilizing the projecting trend of demand towards that spectrum.

- Opportunity Cost of Occupied Spectrum

This approach takes in the same factors as the one without spectrum acquired plus considering potential factors and effectiveness of the business that provides services on the acquired spectrum.

The most crucial step in utilizing opportunity cost approach for spectrum value estimation is the selection of auction bidder representative in order to collect data for analysis. The selection might include typical operators or average operator representatives [7]. Moreover, estimation of of spectrum value by this approach requires various crucial data from bidders, which include current business operation and network infrastructure owned along with data on investment of technologies that bidders plan to operate in their business [1]. As for the estimation of opportunity cost for spectrum value, there are two bottom-up techniques, namely Cost Reduction (CR) Value and Discounted Cash Flow (DCF) Value.

\section{1) Cost reduction value}

Cost Reduction Value (CR) is the assessment derived from 
using spectrum to decrease network deployment costs [7]. "CR is adoption of spectrum to engineer network in capacity constrained cells" [7]. If the operators have few spectrums then they must investment large number of base stations in order to handle excessive traffic generated by the users. In the review of the expert's report, Plum Consulting (2011) CR is considered a best practice and is favored over the use of a cost reduction approach because values based on cost savings rather than cash flows is simpler to calculate, since less few information on future is required [7]. In this approach there is a downward bias set in order to mitigate potential economic losses [7].

The steps concerned in application of Cost Reduction Value approach is shown in the following Table II.

TABLE I: STEPS IN APPLYING THE Cost Reduction VALUe MeTHOD [7]

\begin{tabular}{|c|c|}
\hline Step & Action \\
\hline $\begin{array}{l}\text { 1. Determine network and technology } \\
\text { situation to be modeled }\end{array}$ & $\begin{array}{l}\text { Make assumptions concerning future } \\
\text { network coverage and technology }\end{array}$ \\
\hline $\begin{array}{l}\text { 2. Determine "typical operator } \\
\text { characteristics }\end{array}$ & $\begin{array}{l}\text { Make assumptions concerning } \\
\text { forecast traffic, number of base } \\
\text { stations (actual or modeled based on } \\
\text { link budget and propagation } \\
\text { assumptions), and base line } \\
\text { spectrum assignment. }\end{array}$ \\
\hline $\begin{array}{l}\text { 3. Determine spectrum } \\
\text { increment/decrement }\end{array}$ & $\begin{array}{l}\text { Make assumptions about amount of } \\
\text { spectrum to add/take away from base } \\
\text { line allocation. This is the minimum } \\
\text { amount that can technically can be } \\
\text { used to enhance/reduce capacity }\end{array}$ \\
\hline $\begin{array}{l}\text { 4. Determine the number of base } \\
\text { station sites and amount of network } \\
\text { equipment to deliver traffic }\end{array}$ & $\begin{array}{l}\text { Either model network or use data } \\
\text { from operators to identify initial } \\
\text { number of base stations affected that } \\
\text { are capacity constrained initially. } \\
\text { Model impact of traffic growth on } \\
\text { network quantities in future. }\end{array}$ \\
\hline $\begin{array}{l}\text { 5. Estimate number of base stations } \\
\text { required network costs to support } \\
\text { traffic forecasts with and without } \\
\text { additional spectrum }\end{array}$ & $\begin{array}{l}\text { Model network with and without } \\
\text { spectrum in areas that are capacity } \\
\text { constrained }\end{array}$ \\
\hline $\begin{array}{l}\text { 6. Estimate network costs to support } \\
\text { traffic forecasts with and without } \\
\text { additional spectrum }\end{array}$ & $\begin{array}{l}\text { Change in the number of base } \\
\text { stations will results in change in base } \\
\text { station and backhaul costs. }\end{array}$ \\
\hline $\begin{array}{l}\text { 7. Estimate value of spectrum } \\
\text { increment/decrement }\end{array}$ & $\begin{array}{l}\text { Calculate difference between } \\
\text { network costs with and without } \\
\text { spectrum }\end{array}$ \\
\hline
\end{tabular}

\section{2) Discounted cash flow value}

Discounted Cash Flow (DCF) value is a method of estimation using time value of money method. All "future cash flows are assessed and discounted to give their Present Values (PVs)". Total future cash flows, both received and given out is the Net Present Value (NPV). In simple terms, DCF attempts to find out the value today, based on forecasts of all of the cash that it could make available to investors in the future. It is expressed as "discounted" cash flow because of the principle of "time value of money", meaning cash in the future is worth less than cash today.

Hence, it DCF is also another approach adopted to estimate value of spectrum based on the "expected NPV of future cash flows where these are calculated valuing all other inputs including capital at their market price" [7]. This is the highest value an operator should be paying feor a specific amount of spectrum. Shown in Fig. 1, if payment exceeds this derived value by DCF, then the operator is paying too much [7].

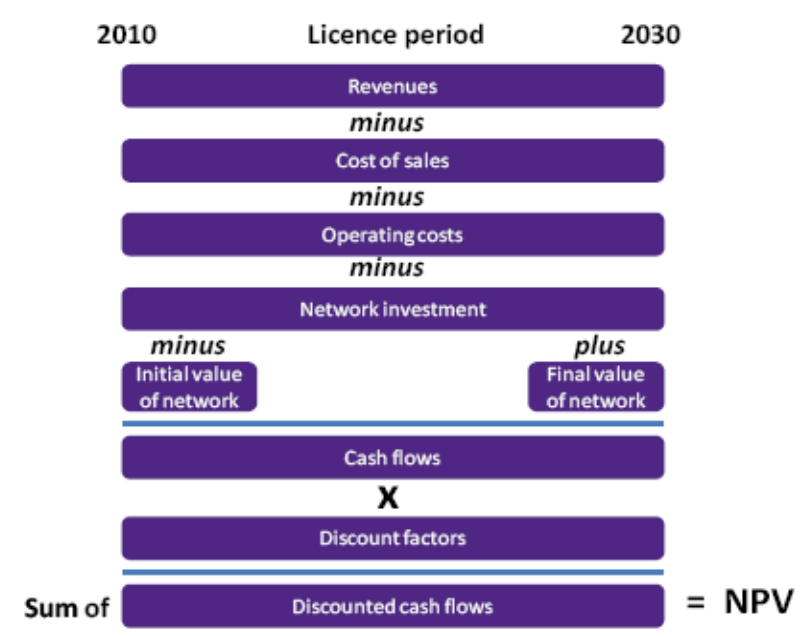

Fig. 1. Calculation process for estimating discounted cash flows [7]

This approach gives extremely unreliable results as it is dependent on forecasts of future revenues over the next two decades and an uncertain relationship between revenue and network capability [7].

\section{E. Relationship between DCF and CR Value Measures}

Economic principles recommend that the spectrum value estimation by NRAs should be conducted through concept of opportunity cost [7]. "This denotes a value that lies between a cost reduction value and a value based on the discounted cash flows received from a given amount of spectrum" [7]. Cost reduction value estimation is always lower than the value based on discounted cash flows because it takes into account incremental revenues [7]. Practically, this approach may not always hold but it is rational to compare cost reduction value with that of discounted cash flow value [7].

\section{F. Econometric Approach}

This approach integrates mathematics, statistics, and economic theory together and applies this towards the estimation of spectrum value. Econometric modeling approach requires the real data occurred from the past in order to general a mathematical model for showing relationships between dependent variables and various factors in the form of independent variables. Moreover, this is a technique that estimates both demand and supply variables, which impact the spectrum valuation. Supply variables include number of spectrum slots to be auctioned per license, total number of spectra to be auctioned, duration of license, etc. As for demand variables, these include Gross Domestic Product (GDP), Per Capita GDP, number of mobile phone users, education level of people, and ratio of telecommunication industry revenue to total revenue. Besides, variables representing change in technology also required as they have direct impact on spectrum valuation in the long run. All in all, Econometric approach assesses spectrum value by using various factors to create a model to estimate the spectrum value, which concentrates on spectrum grouping, spectrum license issuing process, conditions for spectrum fee payment, as well as the impact of domestic economy and market state of business on spectrum valuation.

The econometric approach for spectrum value estimation is arranged into 5 following processes:

- Model Specification - determines the relationships in a 
form of Linear Model or Nonlinear Model

- Data Collection - gathers past data for variables. Mostly in the form of panel data, this comprises of Time-Series Data and Cross-Sectional Data.

- Estimation - estimates coefficient value according to the specified model, which may use Ordinary Least Squares, Generalized Least Squares, Two-Stage Least Squares or other techniques.

- Evaluation of Estimated Model - assesses reliability of model and parameters achieved, which may use t-statistics, F-statistics, R-squared and Adjusted R-squared.

- Forecasting - predicts the spectrum value by taking various factors (which impact on estimated value of the model) into consideration.

Moreover, in considering at both potential costs and revenues, there are various factors that cannot be ignored. Hence, the International Telecommunication Union (ITU) clearly groups them into two categories, namely intrinsic and extrinsic, as shown in Table II.

TABLE II: FACTORS IN ASSESSING SPECTRUM VALUE USING ECONOMETRIC APPROACH (INTERNATIONAL TELECOMMUNICATION UNION) [5]

\begin{tabular}{|c|c|c|}
\hline \multicolumn{2}{|c|}{ Type of Factors } & Determining Factors \\
\hline \multicolumn{2}{|c|}{$\begin{array}{l}\text { Intrinsic } \\
\text { Factors that relate to the spectrum itself } \\
\text { and cannot be changed by any } \\
\text { government }\end{array}$} & $\begin{array}{ll}\text { - } & \text { Propagation } \\
\text { characteristics } \\
\text { - } & \text { Sharing capacity } \\
\text { - } & \text { Profusion of uses } \\
\text { - } & \text { Global and regional } \\
\text { - } & \text { International constraints }\end{array}$ \\
\hline \multirow{3}{*}{\begin{tabular}{|l} 
Extrinsic \\
Factors that utilize \\
differently in each \\
country, whether \\
because of \\
physical or \\
demographic \\
characteristics, \\
cultural, historical, \\
or legal heritage or \\
more significantly, \\
as a consequence \\
of national \\
government \\
policies and \\
regulations.
\end{tabular}} & Physical factors & $\begin{array}{ll}\text { - } & \text { Geography } \\
\text { - } & \text { Climate }\end{array}$ \\
\hline & $\begin{array}{c}\text { Socioeconomic } \\
\text { factors }\end{array}$ & 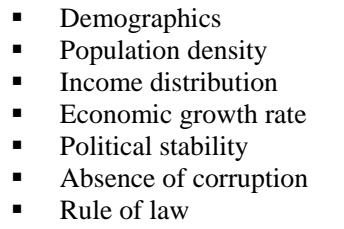 \\
\hline & $\begin{array}{l}\text { Policy and } \\
\text { Regulation }\end{array}$ & 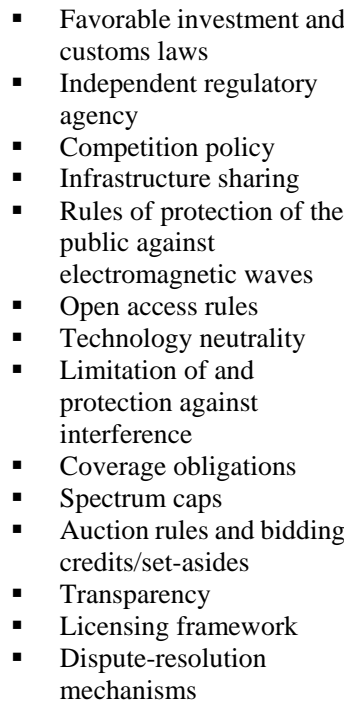 \\
\hline
\end{tabular}

Furthermore, the three standard models of Econometric approach which are appropriate for estimation of spectrum value in Thailand are Least Squares Model, Censored Regression model, and Neural Network Model.

\section{1) Parametric statistics}

Parametric statistics is one that makes assumptions about parameters of the population from which the data is drawn. Generally, parametric methods are suitable when there are non-complex relationships and an assumption can be made to determine the exact relationship between variables. In this research parametric method is classified into two models which are Least Square Model and Censored Regression Model.

\section{- Least Square Model}

The standard Ordinary Least Square (LS) is a model that estimates spectrum value by using standard statistical assumption. In other words, data is normally distributed and parameter estimation values has property of BLUE (Best Linear Unbiased Estimators). In case of data is in forms of Panel Data, there are 3 techniques that can be chosen to evaluate the model, including Pooled Regression Model, Fixed Effect Model, and Random Effect Model.

\section{- Censored Regression Model}

The Censored Regression Model estimates spectrum value from the assumption that some data collected are imperfect in the sense that certain data could not be recorded. In other words, some data are being censored, which results in bias estimation of parameters. Thus, a modified technique called Tobit Model, which utilizes statistical method of Maximum Likelihood Estimation, is appropriate for assessment of parameters. Nonetheless, this model will be accurate only if the data size is large enough.

\section{2) Non-parametric statistics}

Non-parametric method is adopted when parameters or characteristics of the population are unavailable. This method is most favorable when there is a complex relationship between variables or less data availability. In other words, it is suitable when an exact or precise relationship cannot be determined between variables. In this research the non-parametric method adopted is Neural Network Model.

- Neural Network Model

This model utilizes an artificial neural network for discovering a proper relationship between dependent and independent variables. The Neural Network has characteristics of semi-nonparametric model, which is unable to specify functional form to represent a relationship between variables clearly. Additionally, this model is highly flexible in response to changes of data or complication of data. Popular applications of artificial neural network model include Optical Character Recognition (OCR), chemical process control, weather forecast, stock market predictions as well as asset price predictions.

\section{DISCUSSION}

From the variety of aforementioned modeling approaches for spectrum value estimation combined with pros and cons of each approach, Table III gives a summary of strengths and weaknesses of each one in order to find the most appropriate approach for estimation of spectrum value in preparation for last year's Thailand $3 \mathrm{G}$ auction.

Although many countries prefer the use of the estimation of opportunity cost approach to assess the spectrum valuation, however, the chosen estimation of spectrum value for Thailand was Econometric modeling. This is firstly due to the fact that the econometric approach utilizes the real past data 
instead of using the forecast data, which has high level of uncertainty. Secondly, the assigned research team had already possessed good quality database of the past data in hands, therefore, if the team would have to collect a new set of data, especially those in-depth never before revealed business data, the research team would then face many obstacles. Thirdly, the econometric model can easily be adjusted to cope with changes of the factors. Last but not least, the econometric approach has variety of estimation techniques, thus this can simply be crosschecked for the final outcome.

TABLE III: STRENGTHS AND WEAKNESSES OF EACH APPROACH FOR SPECTRUM VALUE ASSESSMENT

\begin{tabular}{|c|c|c|c|c|c|}
\hline Model & Income (Business-Based Value & Economic-Wide & Benchmarking & Econometric & Opportunity Cost \\
\hline Strength & $\begin{array}{l}\text { Obtain analysis of total revenue } \\
\text { and capital investment cost of } \\
\text { the project. }\end{array}$ & $\begin{array}{l}\text { Thorough analysis from } \\
\text { micro to macro levels. }\end{array}$ & Use real data for analysis & $\begin{array}{l}\text { Use real data for analysis and } \\
\text { the estimated model can be } \\
\text { tested for reliability }\end{array}$ & \begin{tabular}{|l} 
Effectively \\
achieve true \\
market value of \\
spectrum
\end{tabular} \\
\hline Weaknes & $\begin{array}{l}\text { Use of insight information } \\
\text { never before revealed to public. } \\
\text { Uncertainty in assessment of } \\
\text { return of investment, future } \\
\text { investment as well as in relying } \\
\text { on over } 10 \text { years of future } \\
\text { monetary value }\end{array}$ & $\begin{array}{l}\text { Overwhelming factors to } \\
\text { take into analysis process } \\
\text { such as GDP, Per Capita } \\
\text { GDP, employment rate, etc. } \\
\text { Lots of information based on } \\
\text { assumptions. } \\
\text { Limited data availability. }\end{array}$ & $\begin{array}{l}\text { Benchmark of spectrum value } \\
\text { varies widely over time, } \\
\text { geography and type of service as } \\
\text { environment changes and timing } \\
\text { of spectrum releases differ. }\end{array}$ & $\begin{array}{l}\text { Require past data of good } \\
\text { quality and large sampling } \\
\text { size for creating specification } \\
\text { of relationships among } \\
\text { variables. }\end{array}$ & $\begin{array}{l}\text { Calculation of } \\
\text { forecast } \\
\text { investment cost. } \\
\text { Several } \\
\text { alternatives for } \\
\text { spectrum usage. } \\
\text { Use of business } \\
\text { confidential data }\end{array}$ \\
\hline
\end{tabular}

The outcome of Thailand's spectrum value estimation is conducted by using three models of the Econometric approach which are Fixed Effects Model, Tobit Model and Neural Network Model. For the parametric method, Data from 17 countries that conducted was analyzed and input into three least square methods which are Random Effect, Fixed Effect and Pooled Regression. It was concluded that for the Least Square method, Fixed Effect provided the best outcome as it was able to define case-specific factors that impacted spectrum value in auctions conducted in each of the 17 countries. Nevertheless, Least Square methods are adopted in cases where data is unbiased and is rather consistent and efficient. Therefore, a second parametric approach which is the censored regression is adopted. Tobit Model is used in this case as it is more appropriate when data is unbiased and there is limited data availability. Lastly, a non-parametric method is adopted as the third approach. In this case, non-parametric approach is also a suitable spectrum value estimation approach as there is no precise relationship between GDP per capita and spectrum value price estimation which is determined in terms of price/MHz/pop.

This estimated value outcome was comparable between Fixed Effects and Tobit Model as both are parametric methods. The results of both models differed by $12 \%$. The non-parametric methods, Neural Network Model had the highest outcome and differ with Fixed Effects which had the lowest result by $45 \%$. Therefore, spectrum value estimation from fixed effects, Tobit Model and Neural Network Model provided a range estimate of what the spectrum value should be. The estimated spectrum value range was then utilized to set the reserve price for $2.1 \mathrm{GHz}$ spectrum auction. Therefore, econometric approach which is one of the most popular model used worldwide for spectrum value estimation was adopted to determine estimated spectrum value and reserve price that has to be set before the auction is commenced.

Nevertheless, after the spectrum auction $2.1 \mathrm{GHz}$ was concluded on $16^{\text {th }}$ October, 2012, the benchmarking approach was adopted to analyze whether the spectrum value earned is suitable

However, benchmarking approach adopted to analyze the spectrum auction price after the auction was concluded. Benchmark approach is an estimation which involves comparison of auction price with that of other countries. This is considered to be the most appropriate spectrum value assessment method as it allows us to compare with international standard. Illustrated in Fig. 2, the outcome of spectrum value outcome of $2.1 \mathrm{GHz}$ is reasonable and appropriate when it is compared with other countries.

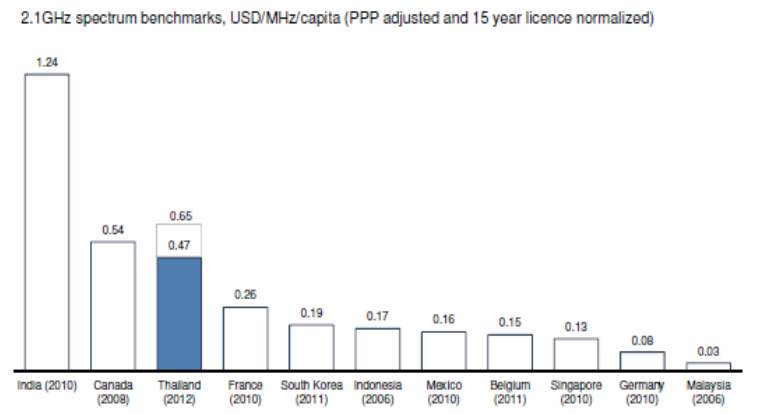

Fig. 2. Benchmarking $2.1 \mathrm{GHz}$ spectrum auction price with other countries [9]

The chart demonstrates the international benchmark for $2.1 \mathrm{GHz}$ auction. The input for the chart which is GDP and license period of each country is normalized to provide equal basis for all countries in order to accrue a methodical and credible benchmark analysis. The auction price earned is higher than wealthier countries such as Malaysia, Germany, Singapore, Mexico, South Korea, Belgium and France that conducted Spectrum auctions recently [9]. The spectrum auction value is also higher than all developing countries except for India. While Thailand had earned USD 0.47 in Spectrum Value price/MHz/Pop, ITU suggests this value is higher than other developing countries and is suitable 
because India and Thailand are amongst the top countries in their growth in demand for Smartphone [10]. As a result, the spectrum value earned is suitable and appropriate as Thailand is expected to experience a tremendous demand for data services [10].

\section{REFERENCES}

[1] B. G. Mölleryd and J. Markendahl, "The Value of Spectrum and the Impact of the Breakthrough for Mobile Data - The Case of India, Sweden and Thailand," Submitted to the Regional ITS Biennial Conference 2012, Bangkok, Thailand, Nov. 18-22, 2012.

[2] J. C. Arnbak, "Managing the radio spectrum in the new environment," in W. H. Melody (ed.), Telecom Reform: Principles, Policies and Regulatory Practices, Lyngby: Technical University of Denmark, pp. 139-147, 1997.

[3] Spectrum Sharing and Tariffs - Impact of Sharing on Prices, International Telecommunications Union (ITU), Regional Seminar Economic and Financial Aspects of Telecommunications Study Group 3, El Salvador, 2011

[4] Opportunity Cost Pricing of Spectrum: Public Consultation on Administrative Pricing for Spectrum Based on Opportunity Cost, Australian Communications and Media Authority (ACMA), April 2009.

[5] Exploring the Value and Economic Valuation of Spectrum. Telecommunication Development Bureau, International Telecommunications Union, Switzerland, Apr 2012.

[6] M. Cave. Review of Radio Spectrum Management. (March 2002). Department of Trade Industry. Her Majesty's Treasury. [Online]. Available:

http://www.ofcom.org.uk/static/archive/ra/spectrum-review/2002revie w/1_whole_job.pdf

[7] Methodologies for Valuing Spectrum: Review of the Experts' Report, Plum Consulting, A Report for Vodafone, March 2011.

[8] P. Marks, K. Pearson, B. Williamson, P. Hansell, and J. Burns, "Estimating the Commercial Trading Value of Spectrum," A Report for Ofcom, Plum Consulting, London, July 2009.

[9] D. P. Arena, Time to stop the uncertainty: $2.1 \mathrm{GHz}$ auction clearly represents fair value and can deliver massive benefits to Thailand.

[10] Thailand 2.1 GHz Spectrum Auction Analysis, ITU Report.

Settapong Malisuwan was born on 24 March 1966 in Bangkok, Thailand. $\mathrm{He}$ received his $\mathrm{PhD}$ in electrical engineering (telecommunications), specializing in mobile communication systems from Florida Atlantic University (State University System of Florida), Boca Raton in 2000. He received an MSc in electrical engineering in mobile communications system, from George Washington University in 1996, an MSc in electrical engineering in telecommunication engineering from Georgia Institute of Technology in 1992 and a BSc in electrical engineering from the Chulachomklao Royal Military Academy, Nakhon-Nayok, Thailand in 1990 He served in the Royal Thai Armed Forces for more than 25 years and is currently the Vice Chairman of National Broadcasting and Telecommunications, Bangkok, Thailand. His research interests are in efficient spectrum management and Telecommunications policy and management in Thailand. Col. Dr. Settapong Malisuwan is currently the Elected Vice Chairman and Board Member in the National Broadcasting and Telecommunications Commission, Thailand.

Thitipong Nandhabiwat was born on 12 April, 1976 in Bangkok, Thailand $\mathrm{He}$ was awarded full scholarship from Rangsit University for his $\mathrm{PhD}$ in information technology from Murdoch University, Perth, Australia. He received MSc on information science from University of Pittsburgh, USA and received a BSc in computer science from University of Waikato, New Zealand. He was the Director in Rangsit University, Thailand and now currently holds a position in National Broadcasting and Telecommunications Commission as an Assistant to Vice Chairman, Bangkok, Thailand since October, 2011. He is also a member in NBTC Subcommittee of Telecommunications for Disaster Prevention and Mitigation. His current research interests is in Robotics, Communications and Computer Networks, and Mobile Applications Development.

Jesada Sivaraks was born on 12 May 1970 in Bangkok, Thailand. He received his MSEE degree from Oklahoma State University in 1996 and BEng from King Mongkut"s Institute of Technology, Thailand. He completed his $\mathrm{PhD}$ in electrical engineering at Florida Atlantic University, Boca Raton, FL in 2001. Since 2011, he has been working in National Broadcasting and Telecommunications Commission as the Secretary to the Vice Chairman. His PhD work is on the system aspects of Bluetooth, WLAN and Mobile IP/CDPD. His current research interests are in telecommunication planning and related system analysis and efficient spectrum management. He is a member of Tau Beta Pi, Florida Epsilon and was an Honorary Advisory's Chairman of Science \& Technology committee of Parliament in 2009.

Navneet Madan was born in Bangkok, Thailand on 22 April, 1987. She received her Bachelor of Business Administration in international business management from Mahidol University in 2008, and received Master of Science degree in strategic management and marketing, Middlesex University, London, United Kingdom. She has been working as an Assistant to Vice Chairman in National Broadcasting and Telecommunications, Bangkok, Thailand since January 2012. Her research interests are in Spectrum Management Strategic Flexibility, Market Orientation and Environmental Uncertainty in Fast Clockspeed Industries.

Pannakorn Laokulrat was in Bangkok, Thailand on 11 June, 1979. She received her Bachelor of Accounting from Bangkok University, Thailand in 2000. She further received MBA from Bangkok University, Thailand in 2008. She has been working as NBTC Officer in National Broadcasting and Telecommunications Commission in Universal Service Bureau (USO) department since 2005. She was promoted and is now working as Assistant to Vice Chairman of NBTC since 2011. Her research interests are in USO, Spectrum Regulatory Policy and Spectrum Efficiency. 